\title{
ANÁLISE MICROESTRUTURAL ENTRE O CONCRETO GEOPOLIMÉRICO E O CONCRETO PORTLAND *
}

\author{
Diegles Simões de Toledo Pereira ${ }^{1}$ \\ Felipe José da Silva² \\ Ana Beatriz Rodrigues Porto ${ }^{3}$ \\ Sérgio Neves Monteiro ${ }^{4}$ \\ Verônica Scarpini Candido 5 \\ Alisson Clay Rios da Silva ${ }^{6}$
}

\section{Resumo}

O alto consumo de energia e a elevada emissão de dióxido de carbono são os maiores problemas da indústria de cimento Portland relacionados à poluição do meio ambiente. Com o objetivo de reduzir estes problemas, os cimentos geopoliméricos despontam como uma nova classe de materiais de alto desempenho e não agressivos ao meio ambiente utilizados como aglomerante mineral capaz de substituir total ou parcialmente o cimento Portland. Estes cimentos são considerados quasi-frágeis devido ao seu comportamento elástico não-linear, provocado pela relaxação e redistribuição de tensões antes da ruptura. Todos os resultados obtidos no programa experimental para o concreto de cimento geopolimérico (CCG) foram comparados com aqueles obtidos para o concreto de cimento Portland (CCP), sob as mesmas condições de ensaio. Neste trabalho, são apresentados resultados de difração de raios-X (DRX), microscopia eletrônica de varredura (MEV) e análise térmica (DSC/TGA), a fim de reunir informações para um melhor entendimento da microestrutura do concreto geopolimérico.

Palavras-chave: Concretos, Geopolímero, Microestrutura.

\section{MICROSTRUCTURAL ANALYSIS BETWEEN THE GEOPOLYMERIC CONCRETE AND PORTLAND CONCRETE}

\section{Abstract}

The high consumption of energy and the elevated emission of carbon dioxide are the biggest problems of the Portland cement industry related to the pollution of the environment. With the objective to reduce these problems, the geopolymer cements appear as a new class of high performance and environment-friendly materials used as binder mineral capable to substitute total or partially the Portland cement. These cements are considered quasi-brittle due to their non linear elastic behaviour, induced by relaxation and redistribution of tensions before the rupture. All the results obtained in the experimental program for the geopolymer concrete (GC) were compared with those obtained for Portland concrete (PC), under the same analysis conditions.In this work, results of X-ray diffraction (XRD), scanning electron microscopy (SEM) and thermal analysis (DSC / TGA) are presented, in order to gather information for a better understanding of the microstructure of the geopolymer concrete.

Keywords: Concrete, Geopolymer, Microstructure.

1 Engenheiro Civil, Mestre em Ciência dos Materiais, Rio de Janeiro, Rio de Janeiro e Brasil.

2 Engenheiro Mecânico, Doutor em Ciência dos Materiais, Professor Adjunto I, Curso de Engenharia Mecânical ,Instituto Federal de Educação, Ciência e Tecnologia, Rio de Janeiro - RJ, Brasil.

3 Graduanda em Engenharia de Materiais, Faculdade de Engenharia de Materiais, Universidade Federal do Pará (UFPA), Ananindeua-PA, Brasil 
4 Engenheiro de Materiais, PhD em Engenharia e Ciência dos Materiais, Professor, Programa de Pós-graduação em Engenharia de Materiais/Departamento de Engenharia mecânica e Materiais, Instituto Militar de Engenharia (IME), Rio de Janeiro, Rio de Janeiro, Brasil.

5 Bióloga, Doutora em Ciência dos Materiais, Professora Adjunta I, Faculdade de Engenharia de Materiais, Universidade Federal do Pará (UFPA), Ananindeua-PA, Brasil.

6 Químico industrial, Doutor em Ciência dos Materiais, Professor Adjunto I, Faculdade de Engenharia de Materiais, Universidade Federal do Pará (UFPA), Ananindeua-PA, Brasil.. 


\section{INTRODUÇÃO}

Os geopolímeros são uma nova família de materiais à base de óxidoaluminossilicatos polimerizados, obtidos por um processo semelhante àquele empregado na síntese de zeólitas cristalinas [1]. O processo consiste na polimerização hidrotérmica em ambiente altamente alcalino.

Dependendo da relação Si/Al, é possível obter produtos com diferentes características. Um arranjo tridimensional, com ligações cruzadas é formado quando a relação $\mathrm{Si} / \mathrm{Al}$ é igual ou superior a 3 . O geopolímero com essas relações atômicas é chamado polissiloxossialato, ou PSS [1,2].

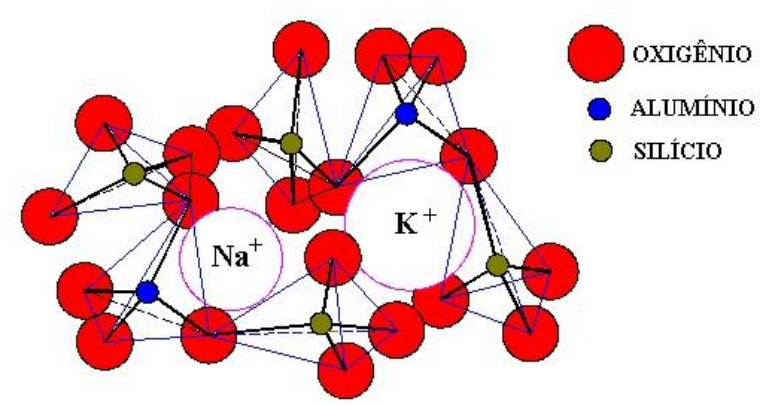

FIGURA 1: REPRESENTAÇÃO ESQUEMÁTICA DO ARRANJO ESPACIAL DA ESTRUTURA DO GEOPOLÍMERO [2].

Os geopolímeros são formados por cadeias ou anéis com $\mathrm{Si}^{4+}$ e $\mathrm{Al}^{3+}$ em número de coordenação IV com o oxigênio, apresentando composição química similar à das zeólitas, mas com estrutura variando de amorfa a semi-cristalina [1].

As diferentes formas de síntese dos geopolímeros são baseadas nas composições molares entre os compostos reagentes, que influenciam diretamente nas propriedades do produto final obtido. As principais matérias-primas utilizadas são o metacaulim, como fonte de silício e alumínio e a escória granulada de altoforno, como fonte de cálcio, além de uma fonte de álcalis $(\mathrm{KOH})$ [3].

O metacaulim é obtido pelo processo de calcinação do caulim, cujo principal componente mineral é a caulinita. A caulinita é um argilomineral, que apresenta a fórmula química $\mathrm{Al}_{2} \mathrm{Si}_{2} \mathrm{O}_{5}(\mathrm{OH})_{4}$ encontrado facilmente na natureza e funciona como fonte de silício e alumínio para os cimentos geopoliméricos. As folhas tetraédricas e octaédricas são contínuas nas direções dos eixos cristalográficos a e b e estão empilhadas umas sobre as outras na direção do eixo cristalográfico c. A FIG. 2 a) apresenta o cristal hexagonal da caulinita e a FIG. 2 b) ilustra o empilhamento das lamelas [4].

O processo de calcinação empregado na obtenção da metacaulinita tem função de remover os grupos estruturais de hidroxila e criar uma instabilidade química pela mudança do número de coordenação do alumínio de VI para IV [4]. Este processamento deve ser capaz de provocar desordem na estrutura cristalina do material para melhorar a sua reatividade na presença dos demais reagentes durante a síntese do geopolímero [3,4].

A escória de alto-forno (EGAF) é um subproduto do processo de metalurgia do aço, que é granulada durante o processo de resfriamento brusco e posteriormente moída. As propriedades físico-químicas da escória granulada de altoforno a tornam um material de grande utilização como adição ao cimento Portland $[3,5]$. 


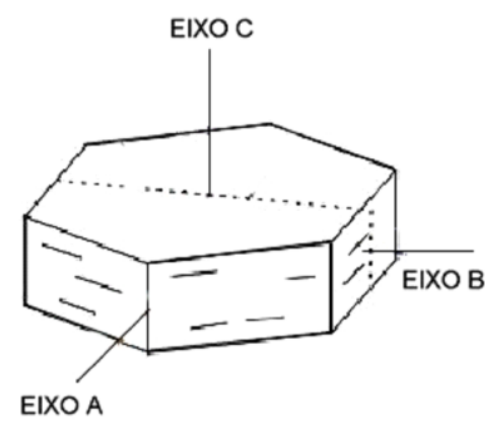

(A)

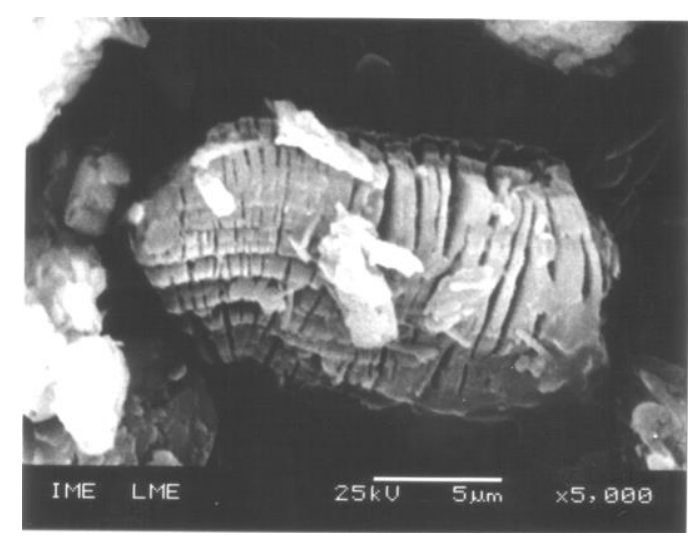

(B)

FIGURA 2. A) REPRESENTAÇÃO DO CRISTAL LAMELAR DE PERFIL HEXAGONAL DA CAULINITA [3]. B) IMAGEM DE ELETRÓNS SECUNDÁRIOS ( $\mathrm{e}^{\square}$ SE) DO CAULIM CALCINADO, OBTIDA POR MEV (5000X).

A produção do concreto geopolimérico constitui uma tecnologia inovadora no ramo da construção civil. O seu desempenho mecânico é compatível aos concretos de alto desempenho. A trabalhabilidade do concreto geopolimérico fresco em relação à do concreto de cimento Portland é mais elevada, permitindo que o uso de plastificante, em muitos casos, seja dispensado. Estudo feito por Thomaz (2000), mostra a obtenção de concretos geopoliméricos com resistência à compressão variando de 45 a $60 \mathrm{MPa}$, com o consumo de aglomerante de $419 \mathrm{~kg} / \mathrm{m}^{3}$ e abatimento de $110 \mathrm{~mm}[6]$.

Neste trabalho, foi realizada a análise microestrutural do concreto geopolimérico e a comparação com análises microestruturais feitas para os concretos à base de cimento Portland encontradas na literatura. $O$ procedimento para caracterização dos materiais, mistura e moldagem, bem como as rupturas dos corpos-de-prova, foram realizados de acordo com as prescrições normativas e procedimentos usuais utilizados para concretos à base de cimento Portland.

A microscopia eletrônica de varredura é de grande valia para análise de superfícies de fratura do concreto. Entretanto, a necessidade do uso de amostras volumosas constitui uma limitação à técnica, já que se torna difícil obter vácuo necessário para realizar a análise. As amostras precisam apresentar superfícies planas e as dimensões máximas entre $10 \mathrm{~mm}$ e $30 \mathrm{~mm}$. Para estudos de interface é comum a observação de superfícies polidas de amostras embutidas em resina.

Análises complementares de difração de raios-X (DRX) e térmicas (DSC e TGA) foram realizadas para a avaliação do grau de cristalinidade, a identificação de fases e a avaliação das transições que ocorrem em função do aquecimento dos materiais.

\section{MATERIAIS E MÉTODOS}

Para produzir o cimento geopolimérico do tipo PSS, a principal fonte de alumínio e silício foi o metacaulim, obtido pela calcinação do caulim fornecido pela Monte Pascoal S.A. Como a relação Si/Al no metacaulim é menor que 3, foi usada uma fonte extra de silício, o silicato de sódio $\left(\mathrm{Na}_{2} \mathrm{SiO}_{3}\right)$. A escória granulada de altoforno, fornecida pela Belgo Mineira S.A., foi utilizada como fonte de cálcio. Devido à necessidade de obter um pH elevado ( $\approx 14)$ para iniciar a polimerização foi utilizada uma fonte suplementar de álcalis, o hidróxido de potássio (KOH)-Panamericana S.A. 
O agregado miúdo utilizado foi uma areia quartzosa de rio, lavada e seca em estufa, aproveitando-se todo o material passante na peneira de 4,8 mm. A TAB. 1, mostra os resultados da caracterização da areia.

TABELA 1 - CARACTERIZAÇÃO DA AREIA

\begin{tabular}{|l|c|c|}
\hline \multicolumn{1}{|c|}{ Descrição } & \multicolumn{2}{c|}{ Resultados } \\
\hline Massa Específica [7] & 2,66 & $\mathrm{~g} / \mathrm{cm}^{3}$ \\
\hline Impurezas Orgânicas [8] & $<300$ & $\mathrm{Ppm}$ \\
\hline Módulo de Finura [9] & 2,60 & - \\
\hline Dimensão Máxima [9] & 2,4 & $\mathrm{Mm}$ \\
\hline
\end{tabular}

O agregado graúdo utilizado foi fornecido pela Pedreira Vigné Ltda e identificado como traquito por ensaio petrográfico. A brita foi lavada durante 0 peneiramento para eliminar o material passante na peneira \#200. A TAB. 2, mostra os resultados da caracterização da brita.

TABELA 2 - CARACTERIZAÇÃO DA BRITA

\begin{tabular}{|l|c|c|}
\hline \multicolumn{1}{|c|}{ Descrição } & \multicolumn{2}{c|}{ Resultados } \\
\hline Massa Específica [10] & 2,68 & $\mathrm{~g} / \mathrm{cm}^{3}$ \\
\hline Módulo de Finura [9] & 6,66 & - \\
\hline Dimensão Máxima [9] & 9,5 & $\mathrm{~mm}$ \\
\hline Abrasão Los Angeles [11] & 33 & $\%$ \\
\hline
\end{tabular}

A composição do traço do concreto geopolimérico foi determinada levando-se em conta as tendências ditadas pelo alto desempenho dos novos concretos A fração volumétrica de agregados utilizada foi de $65 \%$ do volume total e a relação brita/areia, igual a 1,63. A relação água/aglomerante foi fixada em 0,384 . O traço em massa foi: 1:1,56:2,54:0,384 [5].

Com relação as análises microestruturais, as imagens das superfícies de fratura foram obtidas a partir de elétrons secundários e retroespalhados em um microscópio eletrônico de varredura JSM 5800 LV da marca JEOL. A tensão de aceleração do feixe de elétrons gerado a partir de um filamento de tungstênio foi igual a $20 \mathrm{kV}$.

As amostras do concreto foram retiradas da superfície de fratura após o rompimento dos corpos-de-prova em ensaios de compressão. As amostras para análise por elétrons retroespalhados foram embutidas em resina de poliéster e curadas a temperatura ambiente por 24 horas. Em seguida, foi realizado o polimento das amostras em lixas de carbeto de silício números 100, 200, 320, 400 e 600 . O lubrificante utilizado durante o polimento foi álcool etílico (P.A.), para evitar a hidratação do material. As amostras para análises por elétrons secundários não foram polidas. Como as amostras não são condutoras foi necessário a deposição de ouro na superfície para garantir o fluxo de elétrons.

As análises térmicas foram realizadas nos equipamentos TGA-50 e DSC-50, ambos da marca SHIMADZU. Amostras de pastas foram preparadas e convertidas a pó. $\mathrm{O}$ aquecimento ocorreu partindo da temperatura ambiente até $700^{\circ} \mathrm{C}$, com taxa de aquecimento de $20^{\circ} \mathrm{C}$ por minuto, em atmosfera de nitrogênio. 
A caracterização dos materiais por difração de raios-X (DRX) foi realizada em um difratrômetro SIEMENS modelo $\mathrm{D} 5000 \mathrm{com}$ radiação CuK $\alpha$. Os compostos foram identificados por meio de programas-biblioteca padrões. As amostras também foram convertidas a pó.

\section{RESULTADOS E DISCUSSÃO}

A resistência média à compressão do concreto geopolimérico, $f_{\mathrm{cm}}$, com 720 dias foi igual a $61 \mathrm{MPa}$. Um estudo anterior deste mesmo concreto feito por Thomaz (2000) concluiu que a curva experimental para o desenvolvimento de resistência em função do tempo segue aproximadamente a curva de concretos à base de cimento Portland de alta resistência inicial (CPV-ARI). Este tipo de concreto desenvolve uma pequena variação na resistência final, o que pode ser constatado pela comparação da resistência à compressão obtida aos 28 dias de idade igual a $59 \mathrm{MPa}$ e aos 720 dias igual a $61 \mathrm{MPa}$.

A FIG. 4 representa o difratograma do caulim Monte Pascoal, mostrando além da presença da caulinita, a presença do anatásio. O pico intenso da caulinita em $2 \theta$ $\cong 12,5^{\circ}$ corresponde a distância interplanar do plano $\{0001\}$ igual a $7,07 \AA$. O pico da fluorita presente nos difratogramas listados a seguir é devido à adição deste material para análise pelo método de Rietveld.

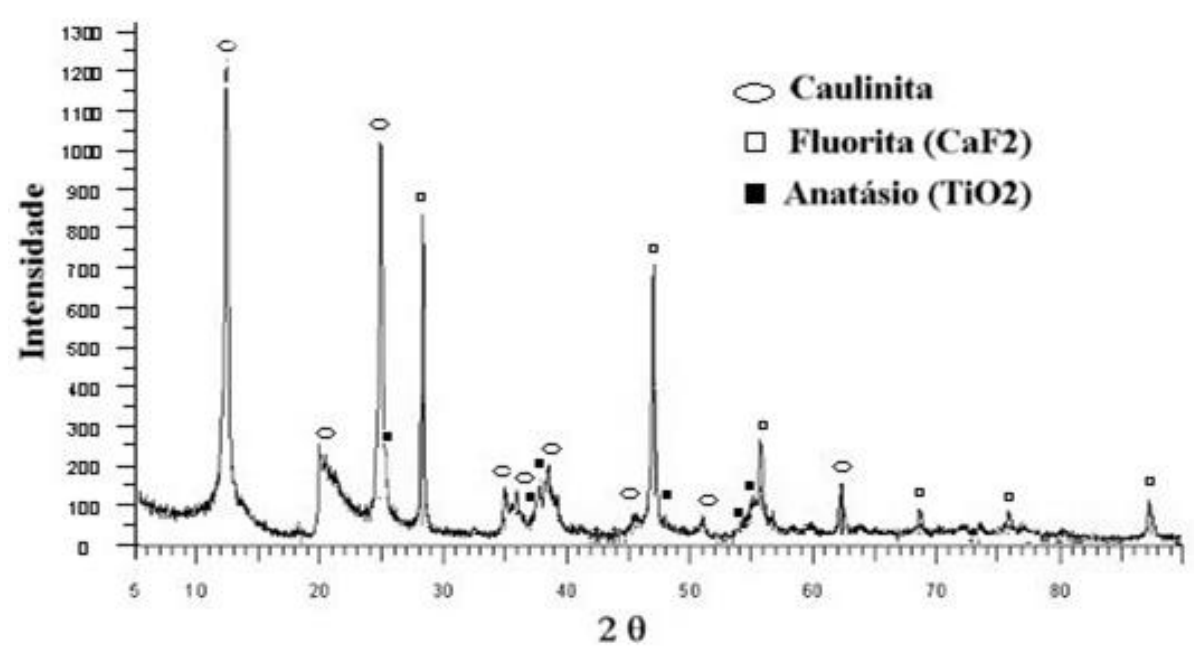

FIGURA 4: DifRATOGRAMA DE RAIOS-X DO CAULIM MONTE PASCOAL.

A calcinação do caulim na temperatura de $700^{\circ} \mathrm{C}$ por 6 horas teve seu efeito identificado pela difração de raios-X (FIG. 5). O difratograma mostra que praticamente toda a caulinita sofreu desidroxilação. A remoção da água estrutural da caulinita ocorre da seguinte forma: $\mathrm{Al}_{2} \mathrm{Si}_{2} \mathrm{O}_{5}(\mathrm{OH})_{4} \rightarrow \mathrm{Al}_{2} \mathrm{Si}_{2} \mathrm{O}_{7}+2 \mathrm{H}_{2} \mathrm{O}$. Pode ser observado que com a combinação do tempo e da temperatura foi possível desorganizar a estrutura da caulinita, tornando-a amorfa (metacaulinita).

O difratograma da FIG. 6 mostra que a pasta de cimento PSS apresenta um pequeno ombro na posição $2 \theta \cong 12,5^{\circ}$ referente a uma fração residual de caulinita $e$ um halo difuso em cerca de $26-27^{\circ}$ referente a aragonita $\left(\mathrm{CaCO}_{3}\right)$, proveniente da escória granulada de alto-forno. 


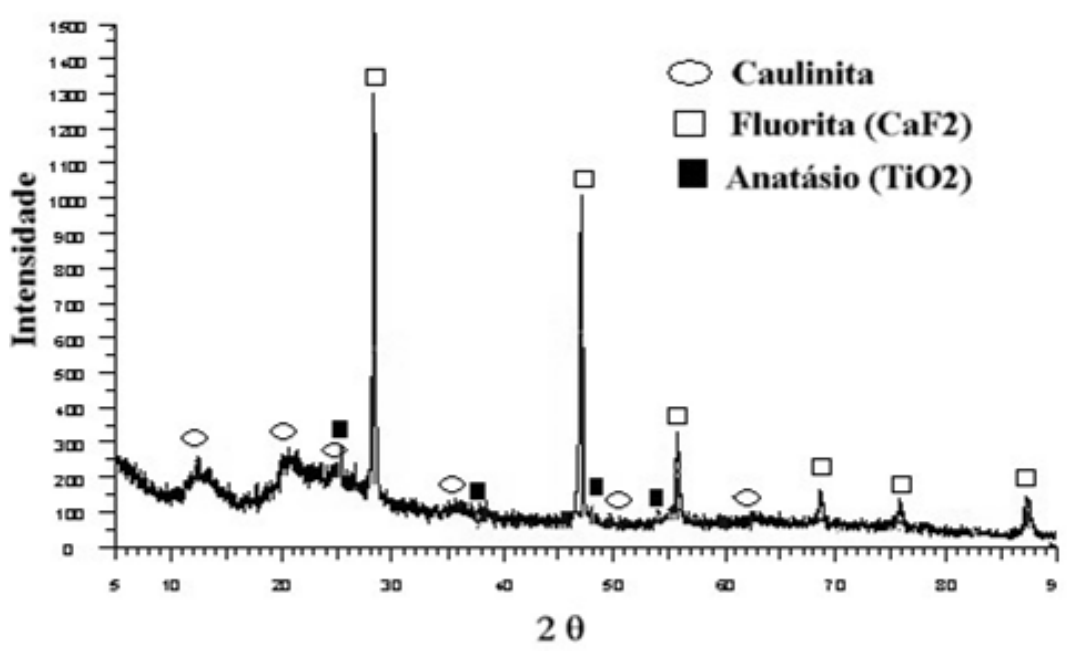

FIGURA 5: DIFRATOGRAMA DE RAIOS-X DO CAULIM CALCINADO POR 6 HORAS.

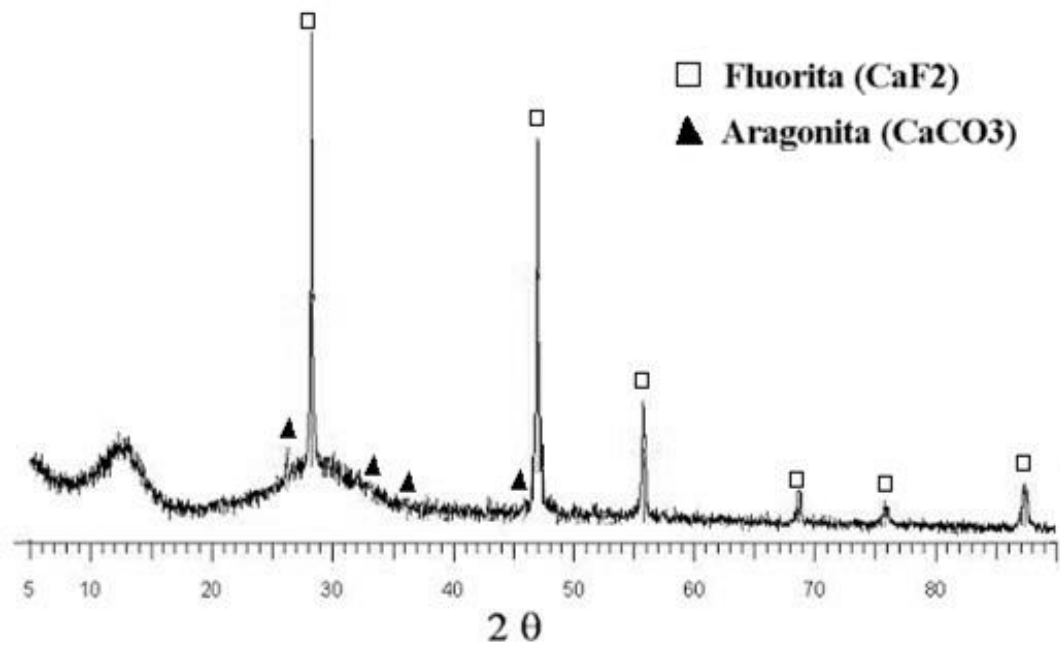

FIGURA 6: DIFRATOGRAMA DE RAIOS-X DO GEOPOLÍMERO (NA,K.CA-PSS).

A FIG. 7, obtida da superfície de fratura do concreto geopolimérico mostra uma excelente distribuição dos agregados na matriz. A inexistência de segregação na matriz é um requisito obrigatório para o bom comportamento deste material em serviço e depende da trabalhabilidade do concreto e das condições de moldagem dos corpos-de-prova. A matriz geopolimérica tem um aspecto mais rugoso do que os agregados.

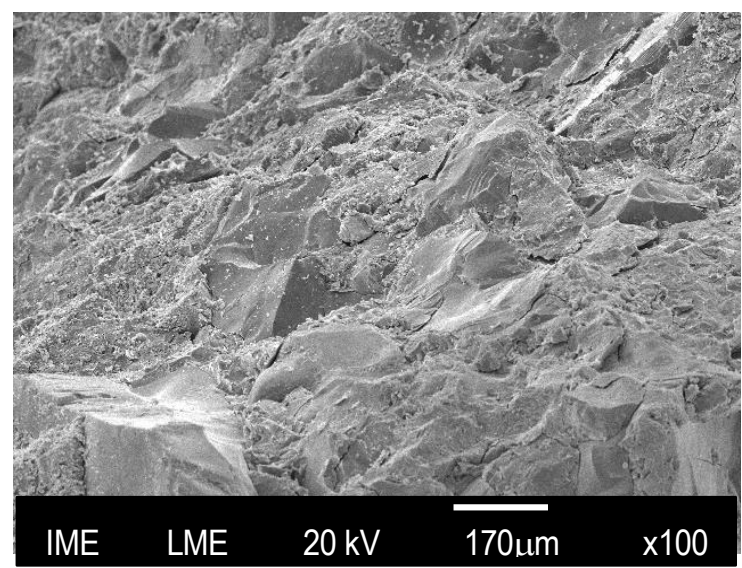

FIGURA 7: IMAGEM DE $\mathrm{e}^{-}$SE DETALHANDO A DISTRIBUIÇÃO DE AGREGADOS NA MATRIZ. 
A FIG. 8 mostra a interface matriz/agregado e a nítida diferença de porosidade do agregado em relação à pasta de cimento. A microestrutura do cimento geopolimérico é massiva, sem morfologia definida, apresentando microfissuras da ordem de $1 \mu \mathrm{m}$. As microfissuras são formadas devido a tensões internas geradas durante as reações de geopolimerização. Para diminuir o efeito destas fissuras no comportamento mecânico do material podem ser utilizadas cargas particuladas (filer) ou fibras [9].

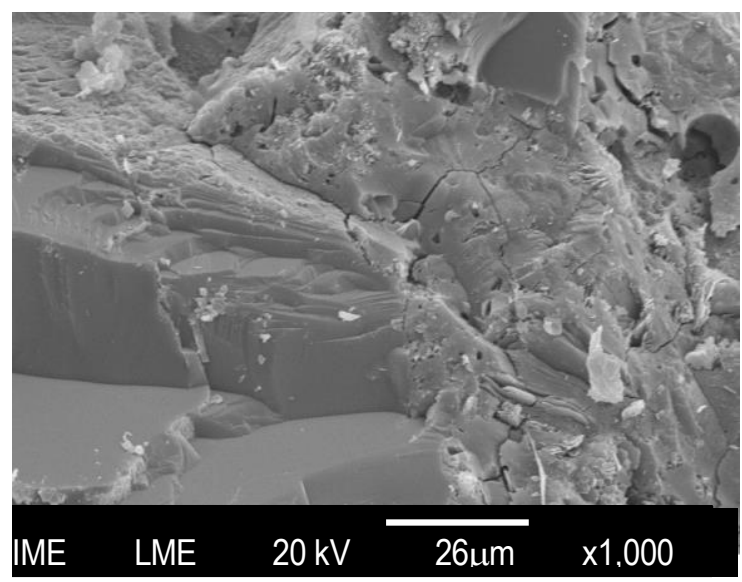

FIGURA 8: IMAGEM DE $\mathrm{e}^{-}$SE, DESTACANDO A DIFERENÇA DE POROSIDADE.

As diferenças microestruturais entre a matriz do concreto geopolimérico (CGP) e a matriz do concreto de cimento Portland (CCP) foram avaliadas pela comparação entre as micrografias obtidas para o CGP e para os concretos de cimento Portland. A FIG. 9, mostra a microestrutura típica de uma pasta de cimento Portland, as três fases identificadas correspondem à cerca de $85 \%$ do volume do material. O número 1 , na micrografia corresponde a Portlandita ou hidróxido de cálcio, o número 2 ao silicato de cálcio hidratado (C-S-H) e o número 3 ao aluminato de cálcio hidratado. A microestrutura do cimento geopolimérico é menos porosa e mais homogênea, sendo formada apenas por uma fase composta de aluminossilicato de sódio, potássio e cálcio.

Estudo da distribuição de cálcio na zona da interface agregado/matriz do concreto geopolimérico não apresentou gradientes de concentração de cálcio [6]. Este fato indica a inexistência da zona de transição entre agregado e matriz no geopolímero. Já no Portland, a região da interface é mais porosa e rica em cristais de Portlandita, podendo limitar consideravelmente as propriedades mecânicas destes materiais devido à baixa aderência entre agregado e matriz. 


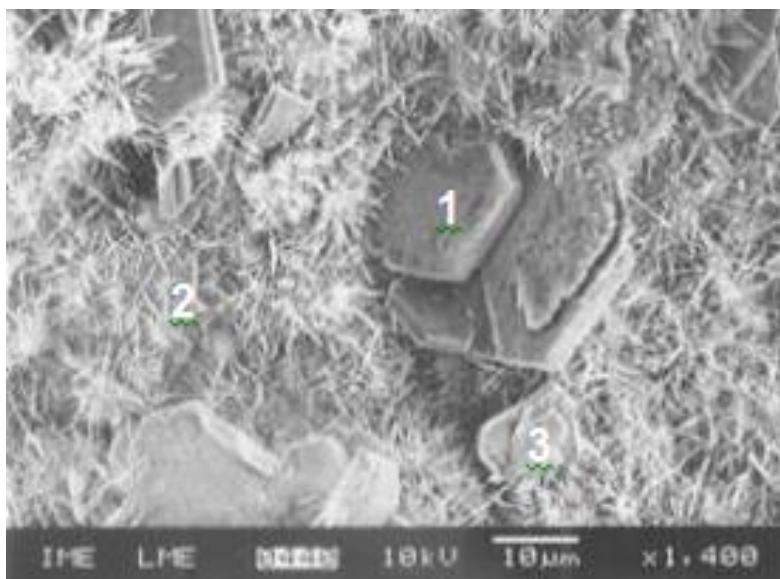

FIGURA 9: IMAGEM DE e-se, DA PASTA DE CIMENTO PORTLAND CPIIE-32, AOS 28 DIAS DE IDADE[4].

Visando complementar a análise microestrutural do CGP e as comparações com o CCP, foram listados a seguir os resultados da análise térmica da pasta de cimento destes concretos.

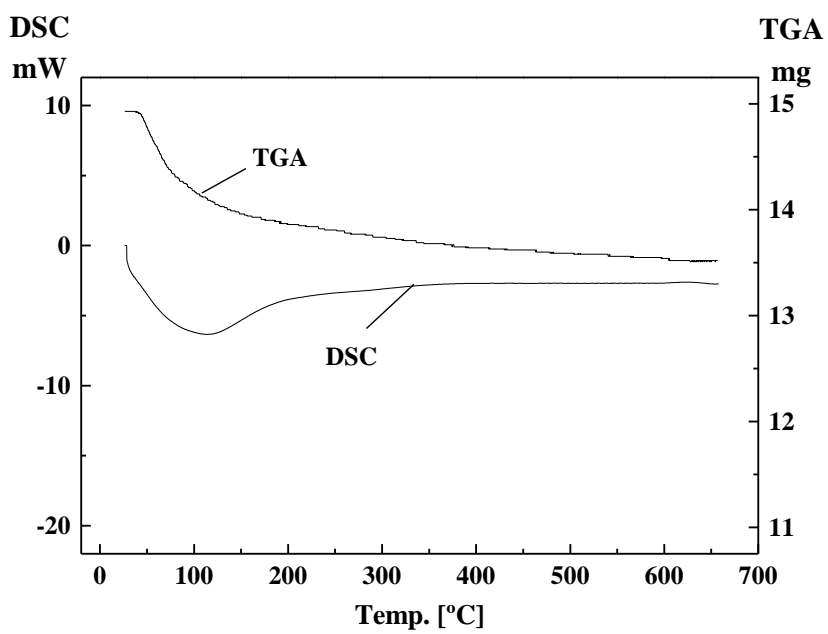

FIGURA 10: CURVAS DE DSC E TGA DA PASTA DE CIMENTO GEOPOLIMÉRICO, AOS 28 DIAS DE IDADE.

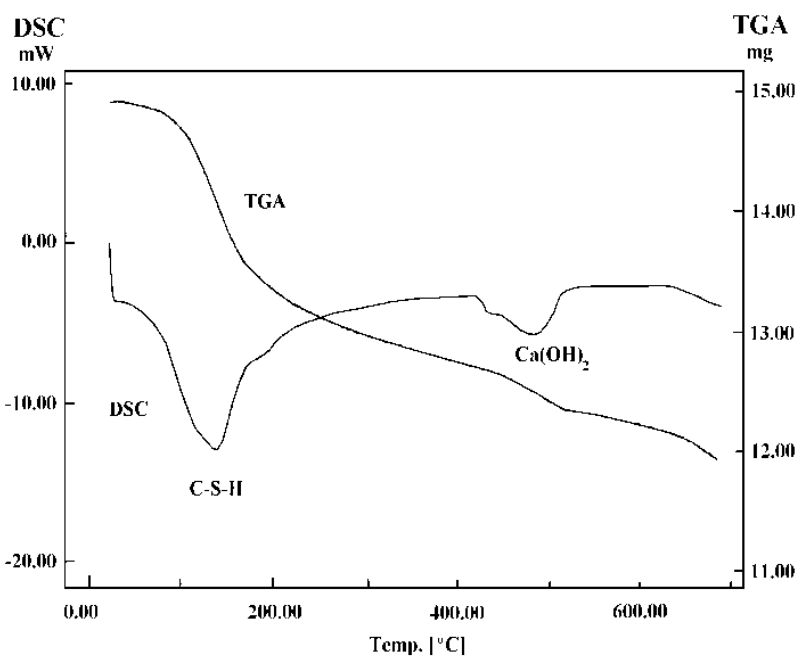

FIGURA 11: CURVAS DE DSC E TGA DA PASTA DE CIMENTO (CPIIE-32), AOS 28 DIAS DE IDADE. [4] 
A pasta de cimento Portland composto apresenta na curva de DSC da FIG. 11 a decomposição da Portlandita em cerca de $480^{\circ} \mathrm{C}$ e a decomposição do $\mathrm{CaCO}_{3}$ em $750^{\circ} \mathrm{C}$. O pico a $145^{\circ} \mathrm{C}$ denota a perda de água livre e adsorvida do $\mathrm{C}-\mathrm{S}-\mathrm{H}$ e a transformação identificada por uma transição a $185^{\circ} \mathrm{C}$ é devido à decomposição das fases Afm. A curva de DSC para a pasta de cimento geopolimérico da FIG.10 não apresentou o pico característico da dissolução da Portlandita, indicando a ausência desta fase no cimento geopolimérico. O pico endotérmico a cerca de $115^{\circ} \mathrm{C}$ é associado à perda de água livre e adsorvida na matriz.

A perda de massa para a pasta de cimento geopolimérico foi igual a 9,61\% (FIG. 10), enquanto que a perda de massa para a pasta de cimento Portland (CPIIE32) foi igual à aproximadamente $20,46 \%$ (FIG. 11).

A composição química dos cimentos geopoliméricos é similar à composição química dos minerais formadores das rochas, o que pode ser comprovado na imagem obtida por elétrons retroespalhados. $O$ contraste de tons de cinza produzido pela diferença de número atômico é praticamente nulo. A imagem da superfície polida do CGP na FIG. 12 mostra as microfissuras na pasta de geopolímero e a maior porosidade da matriz geopolimérica em relação aos agregados, estas diferenças constituem a fonte de contraste da imagem.

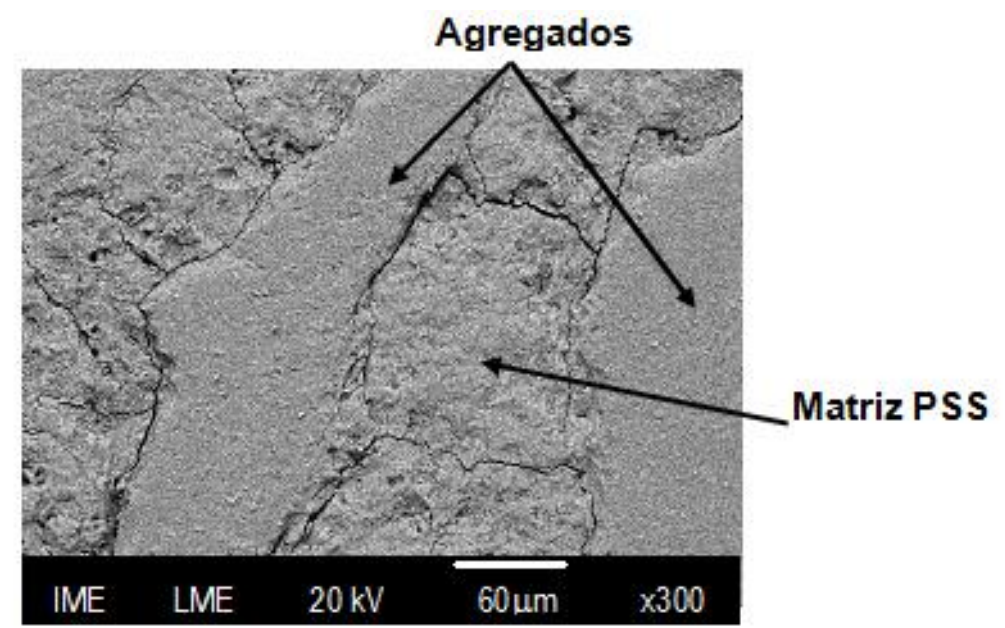

FIGURA 12: IMAGEM DE $\mathrm{e}^{-}{ }^{-}$BSE , DO CONCRETO GEOPOLIMÉRICO, 720 DIAS DE IDADE E A/C=0,384.

A imagem de elétrons retroespalhados da argamassa de cimento Portland gera um contraste que permite a observação das diferentes microestruturas [13]. A identificação de fases é feita através da avaliação dos tons de cinza. Na FIG. 13, é possível perceber que os pontos mais escuros são poros e as superfícies brancas constituem os grãos que ainda não reagiram durante a hidratação. 


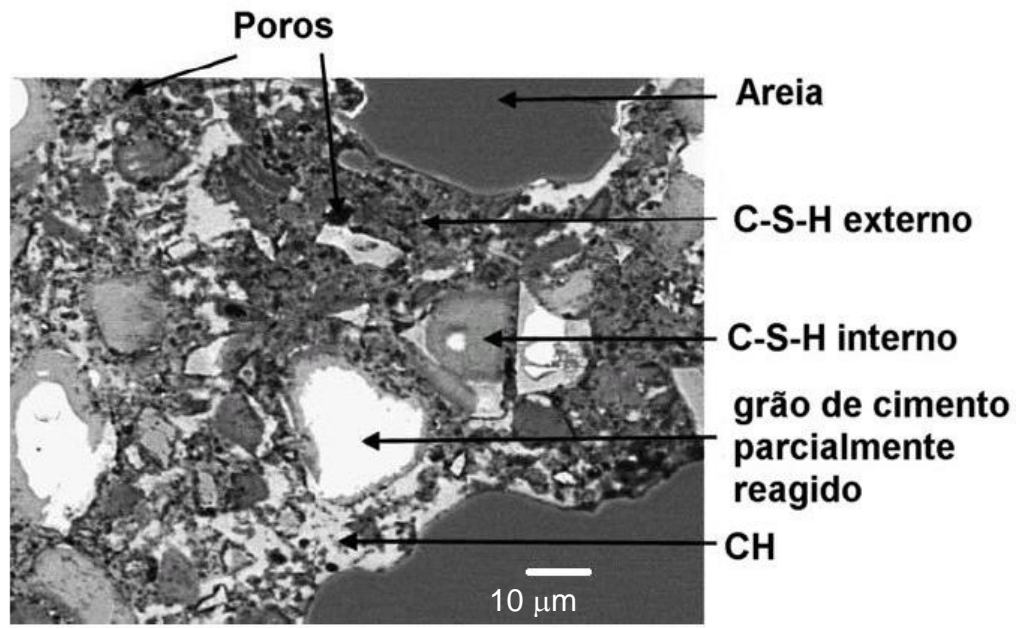

FIGURA 13: IMAGEM DE ${ }^{-}{ }^{-}$BSE,, DE ARGAMASSA DE CIMENTO PORTLAND, 200 DIAS DE IDADE E A/C=0,4 [13].

\section{CONCLUSÕES}

- A partir do difratograma da pasta de cimento geopolimérico é possível constatar que a sua estrutura atômica apresenta baixa cristalinidade. 0 concreto geopolimérico é promissor como material alternativo aos concretos de cimento Portland devido à elevada resistência à compressão e microestrutura densa e isenta de $\mathrm{Ca}(\mathrm{OH})_{2}$.

- A existência de microfissuras na pasta de cimento precisa ser mais bem compreendida para que seja possível aumentar o desempenho dos concretos geopoliméricos. A microestrutura dos concretos de cimento Portland é composta por uma grande diversidade de fases enquanto que o geopolímero é composto basicamente de aluminossilicato de sódio, potássio e cálcio.

- A imagem de elétrons retroespalhados do concreto de cimento geopolimérico não apresenta informações relevantes sobre a diferença de número atômico devido à distribuição homogênea dos elementos químicos, na matriz e nos agregados. A ausência da zona de transição e a afinidade química entre os agregados e a matriz PSS, constituem um indicativo de boa aderência e capacidade de transferência de tensões. Entretanto, a natureza frágil da matriz PSS contribui para o surgimento de inúmeras fissuras microfissuras durante o processo de endurecimento e que devem ser reduzidas pela incorporação de cargas minerais ou fibras.

\section{REFERÊNCIAS}

1 J Davidovits. Geopolymer'88. In: Proceedings of 1th International Conference on Geopolymers; Compiègne; France; 1988; Vol. 1-2.

2 FJ Silva, DP Dias, VFF Barbosa, C Thaumaturgo. High-Performance Mineral Polymeric Binder for Civil Applications. In: II International Conference on High-Performance Concrete, and Performance and Quality of Concrete Structures. Gramado, Brasil; 1999.

3 ACS Rios. Compósitos Geopoliméricos com fibra de carbono para reforço de estruturas de concreto [Tese de Doutorado]. Rio de Janeiro: Instituto Militar de Engenharia (IME); 2010.

4 PS Santos. Ciência e Tecnologia das Argilas. 2a edição revisada e ampliada. São Paulo: Edgard Blücher Ltda. 1989

5 FJ Silva. Reforço e Fratura em Compósitos de Matriz Álcali-ativada [Tese de Doutorado]. Rio de Janeiro: Instituto Militar de Engenharia (IME); 2000. 
6 I Voinovitch, M Raverdy. Slag Cements without clinker. In: Proceedings of International Congress on the Chemistry of Cements. 1980; 122-127.

7 ABNT - Associação Brasileira de Normas Técnicas. NBR NM52 - Agregado miúdo Determinação de massa específica e massa específica aparente. Rio de Janeiro. Set. 2002.

8 ABNT - Associação Brasileira de Normas Técnicas. NBR NM49 - Agregado miúdo Determinação de impurezas orgânicas. Rio de Janeiro. Nov. 2001.

9 ABNT - Associação Brasileira de Normas Técnicas. NBR 7211 (EB4) - Agregado para concreto - Especificação Rio de Janeiro. Março. 2005.

10 ABNT - Associação Brasileira de Normas Técnicas. NBR NM53 Agregado graúdo Determinação de massa específica, massa específica aparente e absorção de água. Rio de Janeiro. Setembro. 2002.

11 ABNT - Associação Brasileira de Normas Técnicas. NBR NM51 - Agregado graúdo Ensaio de abrasão "Los Angeles". Maio. 2001.

12 LG Souza. Geopolímeros à base de resíduos industriais [Tese de Doutorado]; Rio de Janeiro: Instituto Militar de Engenharia (IME); 2005.

$13 \mathrm{KL}$ Scrivener. Backscattered electron imaging of cementitious microstructures: understanding and quantification. Cements \& Concretes Composites. 2004; 26: 935945. 